CASE REPORT

\title{
Fatal pulmonary arterial hypertension associated with phenylpropanolamine exposure
}

\section{R J Barst, L Abenhaim}

Heart 2004;90:e42 (http://www.heartjnl.com/cgi/content/full/90/7/e42). doi: 10.1136/hrt.2004.036491

Exogenous substances such as the appetite suppressant fenfluramine are known to be causally related to the development of pulmonary arterial hypertension (PAH). In these cases, the clinical course as well as the pulmonary vascular disease pathologically is indistinguishable from idiopathic PAH. Other exogenous substances, such as amphetamines, cocaine, and meta-amphetamines, have been considered to be potential risk factors for inducing PAH. SOPHIA (the study of pulmonary hypertension in America), in addition to confirming previous reports of a causal association between the appetite suppressant fenfluramine and $\mathrm{PAH}$, unexpectedly found a significantly increased risk for the development of PAH with exposure to over-the-counter antiobesity agents containing phenylpropanolamine. The first case is reported of fatal PAH in a child heavily treated with cold remedies containing phenylpropanolamine, which, in addition to the results of SOPHIA, strengthens the hypothesis that phenylpropanolamine is a risk factor for the development of PAH.

S OPHIA (the study of pulmonary hypertension in America) unexpectedly found a significantly increased risk for the development of pulmonary arterial hypertension (PAH) with exposure to over the counter antiobesity drugs containing phenylpropanolamine. ${ }^{1}$ We report here a case of idiopathic PAH in a young boy who had a very high exposure to phenylpropanolamine in brompheniramine/ phenylpro (Dimetapp, Wyeth Consumer Healthcare, Madison, New Jersey, USA) that strengthens this association of phenylpropanolamine and PAH.

\section{CASE REPORT}

A 7.5 year old boy was hospitalised with pneumonia seven days before his death in May 1999. On admission he was also noted to have thrombocytopenia, abdominal pain, and a history of two syncopal episodes with exertion the previous week. Echocardiography was remarkable for severe tricuspid regurgitation with an estimated pulmonary artery systolic pressure of $105 \mathrm{~mm} \mathrm{Hg}$. He also had significant right ventricular dysfunction, right ventricular hypertrophy, and a flat interventricular septum consistent with severe PAH. An ECG showed right axis deviation and right ventricular hypertrophy. Chest radiography was remarkable for bilateral perihilar infiltrates, enlarged central pulmonary arteries, and right ventricular enlargement. His complete blood cell count was remarkable for a white cell count of $21500 \times 10^{9} / 1$ with a differential of $64 \%$ polymorphonuclear cells, $22 \%$ lymphocytes, and $11 \%$ monocytes. His haemoglobin was $13.2 \mathrm{~g} / \mathrm{dl}$ with a packed cell volume of $37 \%$ and a platelet count of $46000 \times 10^{9} /$. Arterial blood gas was remarkable for significant respiratory alkalosis with a $\mathrm{pH}$ of 7.6, arterial carbon dioxide pressure $22 \mathrm{~mm} \mathrm{Hg}$, arterial oxygen pressure $55 \mathrm{~mm} \mathrm{Hg}$, bicarbonate $21 \mathrm{mmol} / \mathrm{l}$, base excess $+1 \mathrm{mEq} / \mathrm{l}$, and systemic arterial oxygen saturation 92\% in room air. Ventilation-perfusion lung scan showed low probability of pulmonary embolism, with no segmental perfusion defects. Right heart catheterisation confirmed severe PAH. The pulmonary artery pressure was 150/88 $\mathrm{mm} \mathrm{Hg}$, mean $105 \mathrm{~mm} \mathrm{Hg}$, with a simultaneous systemic arterial pressure $110 / 90 \mathrm{~mm} \mathrm{Hg}$, mean $95 \mathrm{~mm} \mathrm{Hg}$. Right and left heart filling pressures were 14 and $13 \mathrm{~mm} \mathrm{Hg}$, respectively, with a mixed venous oxygen saturation of $31 \%$ and a systemic arterial oxygen saturation of $89 \%$ on $4 \mathrm{l}$ of oxygen by nasal cannula. Additional studies were performed to rule out specific causes for the pulmonary hypertension. Liver function studies showed a mild increase of aspartate aminotransferase. Tests for antinuclear antibodies were negative. Anticardiolipin antibodies were not increased and antithrombin III, protein $\mathrm{C}$, and protein $\mathrm{S}$ concentrations were within normal limits. Erythrocyte sedimentation rate was $6 \mathrm{~mm}$ in the first hour. His family history was unremarkablethat is, there was no family history of pulmonary hypertension, connective tissue disease, congenital heart defects, or haematological abnormalities. The patient died during cardiac catheterisation. On necropsy, he was found to have grade III Heath-Edwards pulmonary vascular changes and endarteritis consistent with severe PAH.

Medical history was remarkable for frequent visits to his paediatrician: at least 40 outpatient visits from December 1992 through December 1998. These visits were for upper respiratory tract infections, sinusitis, and otitis media. He was treated with multiple courses of antibiotics, as well as with Dimetapp containing phenylpropanolamine on at least 35 occasionsthat is, at least five times a year. The Dimetapp was used for a minimum of four days with each course of treatment, for a cumulated exposure of at least four months with a total cumulative phenylpropanolamine dose of at least $5 \mathrm{~g}$.

\section{DISCUSSION}

Classic and severe pulmonary arteriopathy developed in a young child with a history of chronic ingestion of Dimetapp containing phenylpropanolamine. Phenylpropanolamine is a synthetic sympathomimetic amine that was commonly found in appetite suppressants and in cold and cough remedies until it was removed from the market in 2000 due to the risk of haemorrhagic stroke associated with phenylpropanolamine exposure. Case reports, ${ }^{2}$ as well as the case controlled haemorrhagic stroke study reported in 2000, ${ }^{3}$ support the role of phenylpropanolamine in appetite suppressants, as well as possibly in cold and cough remedies, as an independent risk factor for haemorrhagic stroke. Dimetapp subsequently was re-released with pseudoephedrine replacing the phenylpropanolamine.

Exogenous substances such as the appetite suppressants fenfluramine and dexfenfluramine are known to be causally related to the development of $\mathrm{PAH}^{4}$ In these cases, the clinical course as well as the pulmonary vascular disease

Abbreviations: $\mathrm{PAH}$, pulmonary arterial hypertension; SOPHIA, study of pulmonary hypertension in America 
pathologically is indistinguishable from cases of idiopathic $\mathrm{PAH}$ in which no apparent cause can be determined. Other exogenous substances, such as amphetamines and L-tryptophan, and agents such as cocaine and meta-amphetamines, have been considered to be potential risk factors for inducing PAH. ${ }^{5}$ SOPHIA, in addition to confirming previous reports of a causal association between the appetite suppressant fenfluramine derivatives and $\mathrm{PAH}$, also showed a significant association between PAH and over-the-counter antiobesity agents containing phenylpropanolamine. We report the first case of fatal PAH in a child heavily treated with cold remedies containing phenylpropanolamine, which, in addition to the results of SOPHIA, strengthens in our view the hypothesis that phenylpropanolamine is a risk factor for the development of PAH.

Authors' affiliations

R J Barst, Columbia University College of Physicians \& Surgeons, New York, New York, USA

L Abenhaim*, CHU Cochin-Port Royal, Paris, France
*Also McGill University, Jewish General Hospital, Montreal, Quebec, Canada

Correspondence to: Dr Robyn J Barst, Columbia University College of Physicians \& Surgeons, New York, New York, USA; rib3@columbia.edu

Accepted 17 March 2004

\section{REFERENCES}

1 Langleben D, Walker AM, Korelitz JJ, et al. Temporal trends in the number of reported cases of pulmonary hypertension and use of anorexigens, antidepressants, and amphetamines, 1998-2001 [abstract]. Am J Respir Crit Care Med 2004;169:A171.

2 Lake RC, Gallant S, Masson E, et al. Adverse drug effects attributed to phenylpropanolamine: a review of 142 case reports. Am J Med 1990;89:195-208.

3 Kernan WN, Viscoli CM, Brass LM, et al. Phenylpropanolamine and the risk of hemorrhagic stroke. N Engl J Med 2000;343:1826-32.

4 Abenhaim L, Moride Y, Brenot F, et al. Appetite-suppressant drugs and the risk of primary pulmonary hypertension. International primary pulmonary hypertension study group. N Engl J Med 1996;335:609-16.

5 Humbert $M$, Nunes $\mathrm{H}$, Sitbon $\mathrm{O}$, et al. Risk factors for pulmonary arterial hypertension. In: Rich'S, Mclaughlin VV, eds. Clinics in chest medicine. Philadelphia: WB Saunders, 2001:459-75. 